\title{
El fomento del cooperativismo a través de la contratación pública sostenible
}

\author{
Vega María Arnáez Arce ${ }^{1}$
}

Recibido: 28 de junio de 2019 / Aceptado: 20 de noviembre de 2019 / Publicado: 6 de febrero de 2020

Resumen. El nuevo régimen jurídico de la contratación pública ha supuesto una transformación de los contratos del sector público, a los que ha convertido en instrumentos específicos para la consecución de objetivos sociales, ambientales y de emprendimiento e innovación social.

Pues bien, uno de los aspectos más destacados del nuevo régimen de la contratación pública consiste en la consolidación y el desarrollo de los Principios Generales de la Contratación. Principios que, en todo caso y de acuerdo con la Estrategia Europea 2020, precisan ser compatibles con el reto de impulsar la incorporación de cláusulas contractuales que reflejen las obligaciones sociales y medioambientales que deben respetar las Administraciones Públicas y el resto de poderes adjudicadores en los procedimientos de licitación pública.

En este sentido, el trabajo que se presenta aborda el estudio de unos de los retos actuales de la del Movimiento Cooperativo, a partir del análisis de la relación entre la contratación pública y el fomento del cooperativismo como consecuencia de su compromiso social y su contribución, desde su origen a la promoción del desarrollo del interés general en ámbitos tales como la educación, la vivienda, la asistencia socio-sanitaria y la protección y defensa del medioambiente, de acuerdo con los términos del séptimo principio cooperativo que aboga por que estas entidades trabajen en pro del desarrollo sostenible de sus comunidades con arreglo a las políticas adoptadas por sus socios.

Palabras clave: Contratos públicos; Sostenibilidad; Cooperativismo; Cláusula social.

Claves Econlit: K00; K10; K23; H83.

[en] The promotion of cooperativism through public procurement as a challenge and opportunity for the social economy

\begin{abstract}
The new legal regime of public procurement has involved a transformation of public sector contracts, which have become specific instruments for the achievement of social, environmental and entrepreneurial goals and social innovation.

Well, one of the highlights of the new regime of public procurement is the consolidation and development of the General Principles of Contracting. Principles that, in any case and in accordance with the European 2020 Strategy, need to be compatible with the challenge of promoting the incorporation of contractual clauses that reflect the social and environmental obligations that must be respected by Public Administrations and the rest of the contracting authorities in the procedures of public tender.

In this sense, the work presented addresses the study of some of the current challenges of the Cooperative Movement, from the analysis of the relationship between public procurement and the promotion of cooperativism as a consequence of its social commitment and its contribution, from its origin to the promotion of the development of general interest in areas such as education, housing, socio-sanitary assistance and the protection and defense of the environment, in accordance with the terms of the seventh principle cooperative that advocates that these entities work for the sustainable development of their communities according to the policies adopted by their partners.
\end{abstract}

Keywords: Public procurement; Sustainability; Cooperatives; Social clause.

Sumario. 1. Introducción. 2. Aproximación al nuevo régimen jurídico de la contratación pública en el ordenamiento jurídico español. Especial referencia a la incorporación de objetivos sociales y medioambientales. 3. La contratación pública social y medioambientalmente responsable en el ordenamiento jurídico español. 4. El modelo cooperativo como alternativa social sostenible en la nueva contratación pública. 5. Conclusiones. 6. Referencias bibliográficas.

Cómo citar: Arnáez Arce, V.M. (2020) El fomento del cooperativismo a través de la contratación pública sostenible. REVESCO. Revista de Estudios Cooperativos, vol. 133, e67339. https://dx.doi.org/10.5209/REVE.67339.

\footnotetext{
Universidad de Deusto, España

Dirección de correo electrónico: vegamaria.arnaez@deusto.es
} 


\section{Introducción}

El 26 de febrero de 2014, la Unión Europea aprobó un nuevo paquete legislativo en materia de Contratación Pública que se concretó en la promulgación de las siguientes Directivas: Directiva 2014/23/UE sobre adjudicación de contratos de concesión, Directiva 2014/24/UE, general de contratación pública y la Directiva 2014/25/UE, relativa a la contratación pública en los sectores del agua, la energía, los transportes y los servicios postales ${ }^{2}$.

Una de las más importantes novedades que introdujeron las referidas Directivas comunitarias consiste en el desarrollo y consolidación de los principios de la contratación pública, en sintonía y compatibilización con los establecidos en la Estrategia Europea 2020.

En concreto, con su propósito de fomentar la utilización estratégica de los contratos públicos mediante la incorporación de cláusulas que tengan en cuenta criterios sociales y medioambientales a valorar en las licitaciones públicas.

A tal efecto, es importante identificar las condiciones de validez de estos aspectos en los distintos trámites de los procedimientos de contratación, a fin de evitar lesionar o distorsionar el principio de competencia que, como es sabido, constituye su piedra angular básica y está presente, de forma indirecta, en todos los demás principios que la inspiran.

En este contexto, el 8 de noviembre de 2017 se aprobó la vigente Ley 9/2017, de Contratos del Sector Público, por la que se transponen al ordenamiento jurídico español las referidas Directivas del Parlamento y del Consejo 2014/23/UE y 2014/24/UE, de 26 de febrero de 2014.

Habida cuenta de todo ello, el presente trabajo aborda el estudio de uno de los retos actuales del Movimiento Cooperativo, a partir del análisis de la relación existente entre la contratación pública estratégica y el fomento del cooperativismo como consecuencia de su peculiar compromiso social y de su contribución, desde su origen, a la promoción del desarrollo del interés general en ámbitos tales como la educación, la vivienda, la asistencia socio-sanitaria y la protección y defensa del medioambiente, de acuerdo con los términos del séptimo principio cooperativo, que aboga por que sus entidades trabajen en pro del desarrollo sostenible de sus comunidades con arreglo a las políticas adoptadas por sus socios.

\section{Aproximación al nuevo régimen jurídico de la contratación pública en el derecho español. Especial referencia a la incorporación de objetivos sociales y medioambientales}

\subsection{La Estrategia Europea 2020 y las Directivas de cuarta generación}

En la actualidad, en el contexto de un escenario normativo marcado por la denominada Estrategia Europea 2020, la contratación pública juega un papel determinante, al estar configurada como uno de los instrumentos basados en el mercado interior que deben ser utilizados para conseguir un crecimiento económico inteligente, sostenible e integrador, garantizando al mismo tiempo una utilización racional y más eficaz de los fondos públicos.

Con esta finalidad, se aprobaron las tres Directivas comunitarias, como expresión normativa con la que la Unión Europea dio por concluido un proceso de revisión y de modernización de las normas reguladoras de la contratación pública.

Con la aprobación de esta normativa, el objetivo perseguido era incrementar la eficacia del gasto público y facilitar, en particular, la participación en ella de las pequeñas y medianas empresas, así como permitir que los poderes públicos utilicen la contratación pública como instrumento de apoyo y realización de objetivos sociales, al mismo tiempo que garantizar la sostenibilidad de los servicios públicos, especialmente en el ámbito asistencial.

En este sentido, el último paquete de directivas europeas sobre contratación pública - directivas de cuarta generación - ha destacado por ser el primer marco normativo pionero en regular dos aspectos esenciales de la contratación pública: la ejecución de los contratos y las concesiones.

Y ello, por cuanto que ha pasado de limitarse a coordinar los trámites de los procedimientos de adjudicación de los contratos públicos, a regular cuestiones sustantivas tales como el cumplimiento de las obligaciones impuestas, la modificación o la resolución de los contratos y el establecimiento de un marco normativo armonizado, específico y autónomo para las concesiones ${ }^{3}$. 
Aún más, la apertura de la contratación pública al juego de la competencia, junto con la promoción de un crecimiento económico inteligente, sostenible e integrador se han convertido en el punto de partida y de llegada de la nueva normativa vigente en materia de contratación pública.

Merece significarse, a tal efecto, como la citada Estrategia 2020 ya había señalado con anterioridad la importancia de la política de contrataciones como mecanismo garantizador de una utilización y gestión más eficaz de los recursos públicos.

Sin embargo, esta instrumentalización de la contratación pública al servicio de un uso más racional y eficaz de los fondos públicos requiere combinarla, al mismo tiempo, con las reglas de la competencia.

Y así, el artículo 18 de la Directiva 2014/24/UE, relativo a los principios de contratación, establece expresamente que "[...] los poderes adjudicadores tratarán a los operadores económicos en pie de igualdad y sin discriminaciones y actuarán de manera transparente y proporcionada [...]".

Por su parte, la Ley 9/2017, de 8 de noviembre, de Contratos del Sector Público ${ }^{4}$, además de transponer a nuestro ordenamiento jurídico las directivas comunitarias, diseña un sistema de contratación pública más eficiente, transparente e íntegro, con el que alcanzar un mejor cumplimiento de los objetivos públicos, tanto a través de la satisfacción de las necesidades de los órganos de contratación, como mediante una mejora de las condiciones de acceso y participación en las licitaciones públicas de los operadores económicos y, por supuesto, a través de la prestación de los mejores servicios públicos a los ciudadanos.

En definitiva, se puede afirmar que el sistema legal vigente en nuestro país en materia de contratación pública pretende, además de aclarar el marco normativo de aplicación en aras de una mayor seguridad jurídica, promover la utilización de la contratación pública como instrumento para implementar las políticas públicas, europeas y nacionales, en materia social, medioambiental, de innovación y desarrollo, de promoción de las pequeñas y medianas empresas y de defensa de la competencia.

Cuestiones, todas ellas que, de acuerdo con lo dispuesto en el apartado III del Preámbulo de la vigente Ley de Contratos del Sector Público, se erigen como auténticos objetivos de la Ley, persiguiéndose en todo momento la eficiencia en el gasto público y el respeto a los principios de igualdad de trato, no discriminación, transparencia, proporcionalidad e integridad.

\subsection{La incorporación de consideraciones sociales en la contratación pública}

La contratación pública representa aproximadamente el 19\% del PIB europeo y el 18,5\% del PIB español. Pues bien, estos datos respaldan a Gimeno Feliú en su afirmación de que "[...] el impacto económico de los contratos públicos es de tal dimensión que afecta a la consecución del objetivo del mercado interior y desarrollo de la actividad económica transfronteriza" (Gimeno Feliú, 2015: 45).

Por su parte, Burzaco Samper, de un modo más global, considera que "la relevancia de los fondos públicos dedicados a la contratación hace imprescindible una reflexión sobre la viabilidad de alcanzar fines de interés general que trasciendan el objeto propio de cada contrato" (Burzaco Samper, 2016: 281).

En efecto, a la luz de la Estrategia Europa 2020 y con base en el artículo 9 del Tratado de Funcionamiento de la Unión Europea ${ }^{5}$, la contratación pública ha dejado de concebirse como un fin inmediato en exclusiva, pasando a conformar, por razón de su papel capital en la economía, uno de los instrumentos más poderosos para el impulso de otras políticas públicas directas como las de empleo, inclusión, género o medio ambiente.

Y es que, de acuerdo con Rodríguez-Arana Muñoz, la vinculación de la Administración Pública y, por ende, de todas las instituciones administrativas, también del contrato público, al interés general, especialmente en el marco de un Estado social y democrático de Derecho, implica la defensa, protección y promoción de estos y otros aspectos que derivan de la dignidad misma del ser humano (Rodríguez-Arana Muñoz, 2016).

En palabras de Gimeno Feliú, responden al propósito de "[...] garantizar valores superiores del ordenamiento jurídico tan relevantes como son la libertad, la igualdad y la solidaridad" (Gimeno Feliú, 2004: $65)$.

En vista de todo ello, la Unión Europea ha querido dar el empujón legislativo definitivo a la actuación de los contratos públicos como palanca de progreso social y ambiental y, en consecuencia, a su afianzamiento como nueva forma de intervención dentro de la actividad de fomento de la Administración.

El último paquete de directivas sobre contratación viene, por consiguiente, a perfeccionar, sistematizar y desarrollar las escasas previsiones que recogían las normas anteriores al respecto ${ }^{6}$.

Tal como se ha puesto antecedentemente de manifiesto, la Directiva 2014/24/UE, en su artículo 18, obliga a los Estados miembros a adoptar las medidas que aseguren el cumplimiento de las obligaciones sociales y

Boletín Oficial del Estado, núm. 272, de 9 de noviembre de 2017.

Dice así: "En la definición y ejecución de sus políticas y acciones, la Unión tendrá en cuenta las exigencias relacionadas con la promoción de un nivel de empleo elevado, con la garantía de una protección social adecuada, con la lucha contra la exclusión social y con un nivel elevado de educación, formación y protección de la salud humana".

6 Merece destacar que la Directiva 2004/18/CE contemplaba la figura potestativa del contrato reservado en su artículo 19 y la posibilidad de exigir condiciones especiales de tipo social y medioambiental en relación con la ejecución del contrato en su artículo 26. 
medioambientales durante la fase de ejecución. No hay que olvidar que se trata de cláusulas que permiten ir más allá de dicho mínimo legalmente exigido y que generan un valor añadido a los procesos de contratación.

Así pues, en lo que a las reglas que ya comprendía la Directiva previa concierne, es de señalar que, pese a seguir dotando a los contratos reservados de carácter voluntario, el artículo 20 extiende su ámbito de aplicación del marco del empleo protegido a los operadores económicos con fines de integración social y profesional, en general, siempre que al menos un $30 \%$ de sus trabajadores sean personas discapacitadas o desfavorecidas.

El artículo 77 admite, además, que los Estados miembros dispongan que los poderes adjudicadores estén facultados para reservar contratos de servicios sociales a ciertas organizaciones, a las entidades de la economía social, por ejemplo.

Aún más, el artículo 67 recoge otra de las grandes novedades de la Directiva 2014/24/UE, dado que, como bien ha indicado Razquin Lizarraga, sosteniendo como criterio de adjudicación de los contratos el de la oferta económicamente más ventajosa, ha integrado el del coste de ciclo de vida para que sirva de base en su determinación y ha acentuado la preponderancia del de la mejor calidad-precio (Razquin Lizarraga, 2015).

No hay que olvidar, sin embargo, que la principal mejoría, en lo que aquí interesa, es que, a propósito de la evaluación de este último criterio, ha apuntado a las características sociales y medioambientales.

Parece lógico pensar, por lo tanto, que se dan por despejadas las dudas en torno a la legalidad del papel de las cláusulas sociales y medioambientales en la fase de adjudicación. Dicho reconocimiento pasa, eso sí, porque se cumplan tres requisitos indispensables: $i$ ) que estén vinculadas al objeto del contrato, esto es, que "se refieran a las obras, suministros o servicios que deban facilitarse en virtud de dicho contrato, en cualquiera de sus aspectos y en cualquier etapa de su ciclo de vida"; ii) que no confieran al poder adjudicador una libertad de decisión ilimitada, o lo que es lo mismo, que garanticen una competencia efectiva en el mercado y iii) que los pliegos de contratación definan la ponderación que se les atribuye.

Sin embargo, la práctica está evidenciando fuertes disputas entre quienes abogan por la utilización de esta herramienta estratégica en fase de adjudicación, sujetando su validez a la relación con la prestación contractual, y los defensores de la libre competencia, que insisten en el abastecimiento de las Administraciones Públicas y resto de entidades del sector público, de obras, suministros y servicios a través de su adjudicación a las ofertas económicamente más ventajosas como principal objetivo de la contratación, poniendo el acento en la necesaria igualdad entre licitadores.

Por lo demás, mientras que el artículo 43 de la Directiva permite reclamar como medio de prueba una etiqueta determinada en las especificaciones técnicas, criterios de adjudicación o condiciones de ejecución del contrato cuando se tenga la intención de adquirir obras, suministros o servicios con características concretas de tipo social o medioambiental, el artículo 57 enuncia los motivos de exclusión de la participación en los procedimientos de contratación por incumplimiento de la legislación social o medioambiental, citando, entre otros, la infracción de reglas de competencia.

\section{La contratación pública social en el ordenamiento juridico español}

\subsection{Cuestiones generales}

Las transformaciones sociales, económicas y políticas de los últimos años han marcado decisivamente el modo en que las Administraciones y Entidades del sector público gestionan su intervención en los diferentes sectores de actuación y, al mismo tiempo, se han convertido en el origen de la nueva forma de configuración de las denominadas relaciones jurídico-administrativas (Mir Puig, 2004).

Los poderes públicos, por una parte, y las personas físicas y jurídicas de derecho privado, por otro, se han visto avocadas a trabajar de forma conjunta y colaborativa en todo lo que tenga que ver con la satisfacción de las necesidades de interés general y la gestión de los servicios públicos ${ }^{7}$.

Y así, las nuevas fórmulas de gestión pública han optado por la innovación, en todas sus vertientes, como elemento clave para fomentar la eficacia y la eficiencia de la actuación administrativa, por una parte, y, por otra, para garantizar la mejor protección a los ciudadanos, así como la respuesta adecuada a las crecientes demandas sociales y asistenciales de los ciudadanos (Arnáez Arce, 2018).

En este sentido, destaca la inclusión de criterios sociales, junto a los tradicionales de eficiencia y publicidad, en materia de contratación pública. Para ello, el legislador ha establecido una serie de criterios sociales con el propósito de impulsar e incentivar la participación de pequeñas y medianas empresas en el procedimiento de contratación pública.

Véase en este sentido el Preámbulo de la Ley 2/2011, de 4 de marzo, de Economía Sostenible (B.O.E. núm. 55, de 5 de marzo), en el que se afirma la necesidad de impulsar la eficiencia especialmente en el ámbito de la contratación pública y la colaboración entre el sector público y privado como "elementos fundamentales de relación entre la Administración Pública y el tejido empresarial y, a la vez, como ámbitos en los que debe reforzarse la vinculación a parámetros de sostenibilidad económica [...]”. 
Sin embargo, lo que más interesa destacar de la nueva regulación de la contratación pública a partir de las modificaciones incorporadas por las referidas normas legales es su expresa referencia a la necesidad de adoptar medidas específicas para impulsar la denominada cláusula social como un instrumento imprescindible para fomentar y garantizar, de este modo, la gestión y prestación de servicios públicos de calidad y sostenibles, a través de sociedades cooperativas y otras entidades pertenecientes al Tercer Sector económico.

A tal efecto, el nuevo régimen jurídico de la contratación pública incluye, como se ha puesto de manifiesto, criterios y consideraciones de tipo social, medioambiental y de innovación y desarrollo.

Merece significarse, a este respecto, que la introducción de cláusulas sociales y medioambientales en la contratación pública responde al objetivo o finalidad del legislador comunitario de convertir la contratación pública en uno de los motores generadores del bienestar general de los ciudadanos y de la sostenibilidad.

Por este motivo, siguiendo a Martínez Fons, se puede afirmar que "[...] la naturaleza de la cláusula [social y/o medioambiental] y el momento de su inclusión en el procedimiento de contratación pública son los elementos que determinarán los términos de la compleja relación entre aquélla y las reglas que disciplinan la libre concurrencia en el mercado [...]" (Martínez Fons, 2009: 48).

En idéntico sentido, Razquin Lizarraga entiende que la primera forma que tienen estas cláusulas sociales de incorporarse a los procedimientos de contratación pública consiste en establecer los requisitos de carácter social y medioambiental en la propia definición del objeto del contrato, bien en el pliego de cláusulas administrativas generales, o bien en el pliego de cláusulas administrativas particulares, o en el pliego de condiciones técnicas particulares. Incluso la elección de una denominación expresa como "social" o "ambiental" para el contrato tendría una influencia positiva y, sobre todo, lo dotaría de mayor visibilidad (Razquin Lizarraga, 2016).

Otro momento del procedimiento de contratación en el que se deberían considerar los aspectos sociales y medioambientales es la fase de selección, en especial, la acreditación de la solvencia de los licitadores, incluyendo criterios sociales y medioambientales, junto con la solvencia económica y financiera y las capacidades técnica y profesional.

Ello, teniendo en cuenta que el principio de proporcionalidad impide exigir niveles mínimos de solvencia que superen los necesarios para la ejecución del contrato que se va a adjudicar.

Sin embargo, los criterios sociales, y en su caso los medioambientales, siempre que guarden relación con la prestación objeto del contrato, pueden constituir una garantía de su cumplimiento y, por lo tanto, contribuir, también, a la realización de la finalidad propia del referido principio de proporcionalidad.

Aún más, la consideración de este tipo de criterios podría utilizarse como medio de fomento para que los operadores económicos que hasta el momento han relegado a un segundo plano los aspectos relativos a la responsabilidad social corporativa se replanteen, al menos, su posición.

Efectivamente, como condiciones de ejecución de un contrato, el principal reto que afrontan las cláusulas sociales y medioambientales es que, pese a no incidir en la evaluación misma de la oferta y ser, por ello, menos problemáticas para la libre competencia que cuando actúan como criterios de adjudicación, no suelen preverse las medidas oportunas para controlar y sancionar los casos de incumplimiento.

Se puede afirmar, con carácter general, que las cláusulas sociales y medioambientales no tienen cabida en la práctica como criterio de adjudicación, por chocar directamente con los fundamentos del principio de competencia, tal y como la entendemos habitualmente.

En concreto, la Directiva 2014/24/UE, en su artículo 67, recoge los requisitos para su validez en esta fase del procedimiento. De todos modos, en vista del debate que ha abierto la determinación de su alcance, habrá que estar a lo que, tanto la doctrina jurisprudencial, como los Tribunales Administrativos de Contratos, resuelvan al respecto.

Eso sí, la postura que ha adoptado la Unión Europea, en general, y la Directiva 2014/24/UE, en particular, no ofrece ninguna duda sobre el apoyo y la protección que se trata de conferir a las cuestiones de índole social y ambiental, también en el ámbito de los contratos públicos.

Se trata, en definitiva, de un camino de no-retorno emprendido por las instituciones comunitarias que dispondrán, a corto y medio plazo, de nuevas regulaciones que terminen de consolidar la responsabilidad en la contratación pública.

Es por todo ello, por lo que debe ponerse de relieve la ilusión que transmite Lesmes Zabalegui al asegurar que "la incertidumbre existe, pero debemos ser valientes a la hora de avanzar en esta dirección" (Lesmes Zabalegui, 2016: 42).

La clave está en contar con una voluntad clara y un firme compromiso político de ampliar y mejorar las directrices básicas de la Unión Europea e incorporarlas a los ordenamientos internos de los Estados miembros.

Finalmente, y aunque futuras investigaciones puedan orientarse al estudio de otras líneas de actuación en relación, por ejemplo, con los contratos menores, la división en lotes del objeto del contrato o el acceso de las pequeñas y medianas empresas a los procedimientos de contratación, en el presente trabajo se quiere poner de relieve la importancia de reflexionar en torno al propio concepto de "competencia". 
Ello, por cuanto que, si bien es cierto que su condición de elemento cardinal de la contratación pública, ni debe, ni puede, ser discutida y, para ello, procurar su armonización con otros valores recientemente perfeccionados en su sentido e intensificados en su labor, tales como la eficiencia y la integridad, podría evitar muchos dilemas futuros.

\subsection{Algunas consideraciones acerca de las previsiones de la Ley 9/2017, de 8 de noviembre, de Contratos del Sector Público}

La nueva Ley de Contratos del Sector Público establece dos momentos dentro de los procedimientos de contratación en los que se pueden incluir las consideraciones sociales cuales son, la redacción y establecimiento de los criterios de adjudicación, como criterios cualitativos en base a los que evaluar la mejor relación calidad-precio, por una parte y, por otra, mediante su incorporación como condiciones especiales de ejecución de los contratos, siempre que se acredite su relación con el objeto del contrato.

En concreto, en el supuesto de incluirse las consideraciones y aspectos sociales como condiciones especiales de ejecución, la ley impone al órgano de contratación la obligación de que, al menos una de ellas, se corresponda con alguna de las están expresamente enunciadas en el artículo 202 de la vigente Ley de Contratos del Sector Público, relativo a las condiciones especiales de ejecución del contrato de carácter social, ético, medioambiental o de otro orden.

Merece significarse a este respecto que, de acuerdo con lo dispuesto en el apartado 2 del citado artículo 202 de la Ley de Contratos del Sector Público, las consideraciones de tipo social o relativas al empleo podrán introducirse, entre otras, con alguna de las finalidades siguientes:

Hacer efectivos los derechos reconocidos en la Convención de Naciones Unidas sobre los derechos de las personas con discapacidad; contratar un número de personas con discapacidad superior al que exige la legislación nacional;

Promover el empleo de personas con especiales dificultades de inserción en el mercado laboral, en particular de las personas con discapacidad o en situación de riesgo de exclusión social a través de empresas de inserción;

Eliminar las desigualdades entre el hombre y la mujer, favoreciendo la aplicación de medidas que fomenten la igualdad entre mujeres y hombres en el trabajo;

Favorecer la mayor participación de la mujer en el mercado laboral y la conciliación del trabajo y la vida familiar; combatir el paro, en particular el juvenil, el que afecta a las mujeres y el de larga duración; favorecer la formación en el lugar de trabajo;

Garantizar la seguridad y la protección de la salud en el lugar de trabajo y el cumplimiento de los convenios colectivos sectoriales y territoriales aplicables;

- Medidas para prevenir la siniestralidad laboral; otras finalidades que se establezcan con referencia a la estrategia coordinada para el empleo, definida en el artículo 145 del Tratado de Funcionamiento de la Unión Europea;

Garantizar el respeto a los derechos laborales básicos a lo largo de la cadena de producción mediante la exigencia del cumplimiento de las Convenciones fundamentales de la Organización Internacional del Trabajo, incluidas aquellas consideraciones que busquen favorecer a los pequeños productores de países en desarrollo, con los que se mantienen relaciones comerciales que les son favorables tales como el pago de un precio mínimo y una prima a los productores o una mayor transparencia y trazabilidad de toda la cadena comercial.

Todo ello, teniendo en cuenta, además, que una vez establecidas y de acuerdo con lo dispuesto en el apartado 4 del artículo 202 de la Ley de Contratos del Sector Público, todas las condiciones especiales que formen parte del contrato serán exigidas de igual modo a todos los subcontratistas que participen en su ejecución.

En definitiva, en cuanto se refiere a la consideración de los aspectos sociales en la contratación pública, la nueva Ley sigue regulando los contratos reservados a centros especiales de empleo o la posibilidad de reservar su ejecución en el marco de programas de empleo protegido, extendiéndose dicha reserva a las empresas de inserción y exigiéndoles a todas ellas que tengan en plantilla el porcentaje de trabajadores discapacitados que se establezca en su respectiva normativa específica.

En el ámbito de la discapacidad, el artículo 71 de la precitada Ley de Contratos del Sector Público establece como causa de prohibición de contratar con las entidades del sector público el no cumplir el requisito de que al menos el $2 \%$ de los empleados de las empresas de 50 o más trabajadores sean trabajadores con discapacidad, cuestión que ya se había incorporado a nuestro ordenamiento jurídico a través de la modificación del anterior Texto Refundido de la Ley de Contratos del Sector Público, operada por la Ley 40/2015, de 1 de octubre, de Régimen Jurídico del Sector Público.

En idéntico sentido, y con el mismo propósito de impulsar, favorecer y fomentar el respeto de los derechos humanos y, en especial hacía los derechos laborales básicos de las personas trabajadoras y de las 
empresas y pequeños productores de los países en vías de desarrollo, la nueva Ley de Contratos del Sector Público introduce, como se ha señalado antecedentemente, la posibilidad de que tanto los criterios de adjudicación como las condiciones especiales de ejecución de los contratos incorporen aspectos sociales del proceso de producción y comercialización relativos a las obras, suministros o servicios que constituyan el objeto del contrato de que se trate.

\section{El modelo cooperativo como alternativa social sostenible en la nueva contratación pública}

\subsection{Consideraciones iniciales}

El Movimiento cooperativo forma parte del denominado tercer sector, definido como el espacio intermedio existente entre el sector público y el sector privado capitalista que está compuesto por una diversidad de entidades y de organizaciones que trabajan y desarrollan su actividad en un contexto especialmente cambiante, haciéndose cargo de los servicios tradicionales prestados en exclusiva por las Administraciones Públicas (Atxabal Rada, 2018).

El estudio del tercer sector se ha abordado tradicionalmente desde el punto de vista de la transición y evolución de los sujetos económicos hacía la incorporación de valores tales como la mutualidad económica, la gratuidad, la ausencia de intereses particulares y el ánimo de lucro.

En tal sentido, se distinguen dos planteamientos o enfoques para su estudio: el de las organizaciones no lucrativas y el de la denominada economía social.

En cuanto se refiere a las organizaciones sin ánimo de lucro, forman parte del tercer sector aquellas entidades de naturaleza privada, dotadas de personalidad jurídica propia y que estén formalmente organizadas, con una estructura interna y estabilidad en cuanto a desarrollo de actividades y objetivos no lucrativos de interés general.

Según este concepto, forman parte del tercer sector un amplio número de organizaciones, tales como las asociaciones comerciales y profesionales, las organizaciones benéficas tradicionales, las dedicadas al culto o a cuestiones religiosas, las denominadas organizaciones no gubernamentales, las organizaciones de desarrollo popular y los movimientos sociales organizados.

Por otra parte, desde el punto de vista de la economía social y la responsabilidad social corporativa, se le puede definir como el espacio intermedio que existe entre la gestión y la prestación públicas de los servicios sociales y las sociedades mercantiles.

Se trata de un término que se utiliza, por lo tanto, como elemento aglutinador de las instituciones privadas no lucrativas, en cuanto alternativa al mundo de la empresa y al Estado, a través de sus poderes públicos, en cuanto a proveedores de bienes y de servicios de interés general.

En este sentido, se puede afirmar que conforman el tercer sector un conjunto de organizaciones de base privada y de participación voluntaria, dotadas de personalidad jurídica propia, con capacidad de autogobierno que están formalmente organizadas y que no tienen ánimo de lucro, o lo que es lo mismo, no aspiran al reparto entre sus miembros de los beneficios generados por su actividad y que tienen capacidad para autogobernarse y gestionarse de forma independiente.

Dentro de este concepto, destacan en su núcleo central las sociedades cooperativas, las mutualidades, las sociedades laborales, las asociaciones y las fundaciones, en cuanto empresas privadas caracterizadas por la primacía de las personas y de su objeto social frente al capital, de adhesión voluntaria y abierta, en las que los intereses de sus miembros y de sus usuarios, en cuanto a destinatarios o clientes de los bienes y servicios que producen, concurren con el interés general de todos los ciudadanos, al mismo tiempo que se trata de entidades autónomas en independientes respecto de los poderes públicos, que trabajan en defensa de la aplicación y realización de los principios de solidaridad y responsabilidad, mediante la asignación de los excedentes de su actividad a fines sociales tales como la creación de empleo, el fomento de nuevas actividades empresariales, el retorno de los capitales invertidos y el servicio a la comunidad, entre otros (Salas, 2009).

La fundamentación del tercer sector tiene su origen, por lo tanto, en el papel y en las funciones que viene desarrollando en la sociedad. Ello, toda vez que, a diferencia de lo que ocurre con las empresas con fines lucrativos, las entidades que trabajan en este sector actúan satisfaciendo fines e intereses generales, dicho en otras palabras, satisfaciendo demandas que no se expresan en términos económicos o monetarios (Atxabal Rada, 2018).

En la actualidad, en el contexto de crisis económica y social en el que nos vemos inmersos, y en un momento en el que se cuestiona desde todos los puntos de vista el papel del Estado en la planificación y en la ejecución de las políticas públicas, las Administraciones reclaman, cada vez más, la participación y la colaboración activa del denominado tercer sector como agente de innovación que trabaja para la satisfacción eficaz y eficiente de las demandas sociales. 
Asistimos, en definitiva, a un momento de impulso y fomento del papel de este tipo de organizaciones y formas de empresa en el diseño, la planificación, la ejecución y la evaluación de las políticas públicas y de los servicios de interés general, en colaboración con la actividad que en tales materias llevan a cabo las Administraciones y las Entidades del Sector Público.

Un nuevo paradigma estructural y funcional, así como de interacción con los ciudadanos, un reto para el Derecho administrativo y su propósito de alcanzar un auténtico desarrollo institucional, económico y social sostenible.

En definitiva, una oportunidad para obtener servicios públicos especializados, innovadores y sostenible. Aún más, se abre la puerta, asimismo, a la posibilidad de que los agentes públicos incorporen a su actuación los esquemas éticos y las prácticas responsables que presiden el día a día de otros sectores económicos y sociales entre los que destacamos en este trabajo los del Movimiento Cooperativo (Arnáez Arce, 2018).

Ello, como consecuencia de la reestructuración del Estado del bienestar en el que el Movimiento Cooperativo ha venido completando de forma reiterada con su actividad la función atribuida por el ordenamiento jurídico a los poderes públicos, consistente en atender a las demandas y necesidades sociales de los ciudadanos, contribuyendo así a la mejora de sus condiciones de vida y a la consecución, en definitiva, de mayores cotas de bienestar social (Jiménez Escobar; Morales Gutiérrez, 2006).

\subsection{El movimiento cooperativo y su identidad}

De acuerdo con la Declaración de Identidad Cooperativa aprobada en el año 1995 por la Asamblea General de la Alianza Cooperativa Internacional ${ }^{8}$, la cooperativa puede definirse como una asociación autónoma de personas unidas voluntariamente para hacer frente a necesidades y aspiraciones comunes a través de una empresa de propiedad conjunta y democráticamente controlada, regida por un sistema singular de principios y valores (Morillas, 2008).

Precisamente, lo que distingue a las sociedades cooperativas del resto de organizaciones y formas de empresa que operan en el mercado, no es tanto la clase de actividad que desempeñan, como la naturaleza intrínseca que refleja los principios y valores rectores de su organización y funcionamiento. $\mathrm{Y}$ es que encuentran sus bases en la autoayuda, la responsabilidad, la democracia, la igualdad, la equidad y la solidaridad.

Valores que, conforme a la precitada Declaración, se ponen en práctica por medio de los siguientes principios: adhesión voluntaria y abierta; gestión democrática; participación económica; autonomía e independencia; educación, capacitación e información; cooperación entre cooperativas; e interés por la comunidad.

En el supuesto que nos ocupa, a saber, la adjudicación de contratos púbicos a las sociedades cooperativas cobra especial importancia el séptimo principio cooperativo, que aboga por que estas entidades trabajen en pro del desarrollo sostenible de sus comunidades con arreglo a las políticas adoptadas por sus socios.

Según Gadea Soler, Sacristán Bergia y Vargas Vasserot, esto significa que, en las cooperativas, las acciones socialmente responsables no vienen determinadas por motivos externos -comerciales, principalmente-, sino que están medularmente ligadas a su identidad (Gadea, Sacristán, Vargas, 2009).

Es decir, es su propio carácter servicial lo que las conduce a favorecer el progreso socioeconómico de sus miembros y de su entorno, mirando siempre al futuro de las generaciones de hoy y de mañana (Giraldo, 2003).

Por consiguiente, se puede afirmar que el Movimiento Cooperativo ha destacado desde sus orígenes por mantener un fuerte compromiso con la sociedad. Es más, suele presumirse que todas aquellas cooperativas que integran en su objeto social como fines prioritarios de su actuación la educación, la vivienda, la atención socio-sanitaria, la cooperación para el desarrollo o el medioambiente, entre otros, contribuyen, de alguna manera, a la mejor y más eficiente protección y garantía de los intereses generales (Arnáez Arce, 2018).

Ahora bien, son las cooperativas sin ánimo de lucro y, dentro de éstas, las calificadas como de iniciativa social, las que responden a los mismos de una manera más concreta.

Es por todo ello que, las Administraciones Públicas, en el contexto actual de una economía global marcada por la crisis sistémica y el aumento de las desigualdades, precisan, cada vez más, del apoyo y la participación activa de las sociedades cooperativas, las calificadas como de iniciativa social en particular, como agentes de desarrollo e innovación arraigados en nuestra comunidad y que conviven en armonía con ella, para la satisfacción eficaz y eficiente de las necesidades básicas de la ciudadanía.

Y ello, en la medida en que su fundamentación parte del papel y de las funciones que el Movimiento Cooperativo viene llevando a cabo en la sociedad, toda vez que, a diferencia de lo que ocurre con las empresas capitalistas, las entidades que lo conforman persiguen objetivos y tratan de dar respuesta a demandas que no se expresan en términos meramente económicos o monetarios. 


\subsection{El movimiento cooperativo y la contratación pública socialmente responsable}

La simplificación administrativa se presenta hoy como uno de los mayores retos y como el objetivo más inmediato del Derecho administrativo de nuestros días, esencial para la construcción de un nuevo modelo de Administración Pública que sirva con objetividad los intereses generales y actúe de acuerdo con los principios proclamados en el artículo 131 de la Constitución (Palomar, 2010).

Se trata, en definitiva, de un nuevo paradigma estructural y funcional, así como de interacción con los ciudadanos que pretende garantizar e impulsar un desarrollo institucional, económica y social sostenible.

$\mathrm{Al}$ efecto, el fenómeno de la externalización se configura como una tendencia imparable de transformación de las Administraciones que, impulsado por las corrientes doctrinales de la denominada Nueva Gestión Pública, posibilita la incorporación a las mismas de destrezas y habilidades técnicas provenientes del resto de sectores, lo que se traduce en una gran oportunidad de obtener servicios públicos especializados e innovadores.

Por consiguiente, cabe apuntar a la gestión de ciertos servicios públicos a través de la adjudicación de contratos del sector público a sociedades cooperativas, como uno de los elementos clave en la instauración de una Administración Pública que tenga como meta la realización de los principios constitucionales de eficacia y eficiencia y, a su vez, la protección de los aspectos más sólidos del modelo productivo del sector en que se integra.

Un protagonismo o, cuando menos, una creciente relevancia que, para Argudo Périz, estaría justificada por la vocación social y comunitaria y el desarrollo en el sector de servicios del cooperativismo. En palabras del propio autor, tales argumentos determinan necesariamente "una confluencia en el campo de los servicios a las personas y a la comunidad [...]" (Argudo, 2007: 182).

Confluencia que el Tribunal de Justicia de la Unión Europea, en su sentencia de 28 de enero de 2016, ha respaldado expresamente respecto al ámbito de las prestaciones de índole social y sanitaria, por considerar que el Derecho de la Unión no se opone a las normativas nacionales que permiten a las autoridades locales atribuir la prestación de ciertos servicios mediante adjudicación directa, sin forma alguna de publicidad, a entidades sin ánimo de lucro, siempre que el marco legal y convencional en el que actúan contribuya realmente a una finalidad social y a la consecución de objetivos de solidaridad y eficiencia presupuestaria (Gimeno Feliú, 2016).

\subsection{Especial consideración del modelo cooperativo en su contribución a la gestión sostenible de los servicios públicos}

La principal ventaja que representan las sociedades cooperativas para el sistema es, de acuerdo con Álvarez Rodríguez, "la generación de economías de proximidad", como resultado de su especial enlace al territorio y a sus gentes (Álvarez, 2012: 410). Vínculo que, entendemos, deriva a su vez de la idiosincrasia participativa de estas entidades.

En palabras de Divar Garteiz-Aurrecoa “(...) en las cooperativas, la participación de sus miembros es su fuerza endógena (...)” (Divar, 2010: 265).

Es decir, bien su régimen particular de propiedad y de distribución de ganancias, bien el carácter democrático que debe ostentar su gestión, las separan de las estructuras de poder capitalistas y justifican su intenso arraigo social, su tendencia a la creación de empleo estable y de calidad, su flexibilidad para adaptarse a cambios y afrontar crisis y, a fin de cuentas, su potencialidad para conformar una alternativa sólida que impulse un verdadero desarrollo local sostenible.

Es por ello que nos parece esencial ofrecer una breve reflexión en torno al significado y el alcance de la colaboración del mundo cooperativo en la prestación de servicios públicos, como expresión de la evolución del rol de los ciudadanos en sus relaciones con los poderes públicos; una ciudadanía cada vez más exigente a la hora de conocer, influir y formar parte de cuantas decisiones afectan al funcionamiento de unos servicios públicos a cuyo mantenimiento contribuyen con el pago de sus impuestos (Atxabal Rada, 2018).

En esta línea, debe señalarse que el Derecho administrativo actual trata de introducir un nuevo modelo de gestión pública que se nutra de unas instituciones y represente unas prácticas más abiertas y accesibles, con una creciente implicación de los administrados en ellas. O lo que es lo mismo, que fomente una ciudadanía informada, dinámica y corresponsable para con la actividad de la Administración, en la que la prestación coparticipada de servicios públicos goce de mayor protagonismo (Arnáez Arce, 2018).

Sin embargo, cabe advertir que es el Derecho cooperativo el que, desde sus inicios, ha apuntado a la necesidad de que las Administraciones Públicas respalden esta otra forma de hacer empresa, más solidaria y cercana, que supone el fenómeno cooperativo y colaboren con él para el correcto desempeño de sus funciones y la consecución de su fin último, el bienestar común.

Así pues, el artículo 108 de la Ley 27/1999 de Cooperativas anuncia como tarea de interés general el fomento del cooperativismo. Cometido que encuentra su punto de partida y de llegada en la propia Constitución, por concederle ésta en su artículo 129.2 un reconocimiento expreso que asegura su desarrollo 
formal y funcional e integrarlo, al mismo tiempo, como vía para el cumplimiento de los objetivos de contenido social que procura. Y ello, con el propósito de potenciar, no sólo la figura más clásica de la economía social, sino, sobre todo, la más representativa de sociedad participativa (Gallastegi, 2016).

Habida cuenta de todo lo anterior, se puede afirmar que la colaboración con cooperativas se manifiesta, no sólo como la opción preferente para dar respuesta a las necesidades sociales no suficientemente cubiertas por el Estado, sino también como la forma idea para que los ciudadanos participen más y mejor en los asuntos públicos. Para que, toda vez que se respeten los valores y principios cooperativos, los usuarios de los servicios públicos sean tomados en cuenta para su diseño, planificación y prestación, en aras de su accesibilidad e integridad y, por ende, su calidad.

Y es que no se equivocan Juliá Igual y Meliá Martí al sostener que "[...] las cooperativas, hoy más que nunca, están llamadas a ser un elemento clave y dinamizador de un verdadero desarrollo social, económico y sostenible, ya que por sus especiales características permiten que éste sea más cohesionado social y territorialmente, algo a lo que una sociedad más justa y equitativa no puede renunciar" (Juliá y Meliá, 2004: 56).

Todo ello, no olvidemos, en su apuesta por el desarrollo sostenible y la cohesión social y territorial de la Comunidad, trasladando a la práctica los principios y valores cooperativos. Y en ese desafío, las sociedades cooperativas en general y las calificadas como de iniciativa social y/o de utilidad pública, en particular, vienen desempeñando un papel elemental, por tratar de satisfacer necesidades colectivas de toda índole en aquellos espacios que el Sector Público no ha podido cubrir o no ha cubierto como corresponde.

Contribuyendo, en definitiva, a la realización de finalidades públicas y de servicio a la sociedad.

\section{Conclusiones}

Primera. En el contexto actual, en el que se pone en cuestión el funcionamiento y la validez del Estado del Bienestar, las Administraciones y Entidades del Sector Público necesitan, cada vez con más intensidad, la intervención y participación activa en la gestión de los servicios públicos de todos los agentes económicos y sociales de innovación, que tengan entre sus retos y objetivos la satisfacción eficaz, eficiente y sostenible de las necesidades sociales asistenciales, que no se expresan en términos meramente económicos o monetarios.

En este contexto, el proceso de reestructuración, reforma e innovación del sector público, en el sentido de potenciar su competitividad, eficacia y eficiencia, apuesta por una mayor y más real interacción con los ciudadanos quienes, a su vez, demandan un papel cada vez más activo en la planificación, ejecución y evaluación de las políticas públicas que tienen por objeto la prestación de servicios asistenciales a la población.

Segunda. El Movimiento Cooperativo y las organizaciones que lo integran, basan su actuación en los valores de solidaridad, democracia, equidad, igualdad, autoayuda y auto-responsabilidad y ha destacado desde su origen por su contribución a la promoción del desarrollo y a la realización de fines de interés general, de tal forma y manera que, resulta incuestionable que todas aquellas cooperativas que integren en su objeto social fines prioritarios tales como la asistencia socio-sanitaria, la educación, la vivienda, la protección y defensa del medio ambiente, el fomento de la economía social y la protección de la paz social y ciudadana, entre otros, gozan de una presunción de servicio al interés general.

Tercera. La principal ventaja que representan las sociedades cooperativas como coadyuvantes de los poderes públicos en la gestión y prestación de los servicios públicos consiste en su régimen particular de propiedad y de distribución de ganancias, así como el carácter democrático que debe ostentar su gestión. Características, todas ellas que las separan de las estructuras de poder capitalistas y justifican su intenso arraigo social, su tendencia a la creación de empleo estable y de calidad, su flexibilidad para adaptarse a cambios y afrontar crisis y, a fin de cuentas, su potencialidad para conformar una alternativa sólida que impulse un verdadero desarrollo local sostenible.

Cuarta. El Derecho administrativo actual trata de introducir un nuevo modelo de gestión pública que se nutra de unas instituciones y represente unas prácticas más abiertas y accesibles, con una creciente implicación de los administrados en ellas. O lo que es lo mismo, que fomente una ciudadanía informada, dinámica y corresponsable para con la actividad de la Administración, en la que la prestación coparticipada de servicios públicos goce de mayor protagonismo.

Se destaca en este trabajo la importancia de la colaboración del mundo cooperativo en la prestación de servicios públicos, como oportunidad para concretar y materializar el nuevo rol de los ciudadanos en sus relaciones con los poderes públicos, como una ciudadanía cada vez más exigente a la hora de conocer, influir y formar parte de cuantas decisiones afectan al funcionamiento de unos servicios públicos a cuyo mantenimiento contribuyen con el pago de sus impuestos.

Quinta. Desde sus inicios, el Derecho cooperativo ha apelado a la necesidad de que las Administraciones Públicas respalden esta otra forma de hacer empresa, más solidaria y cercana, que supone el fenómeno 
cooperativo y colaboren con él para el correcto desempeño de sus funciones y la consecución de su fin último, el bienestar común.

Así pues, el artículo 108 de la Ley 27/1999 de Cooperativas anuncia como tarea de interés general el fomento del cooperativismo, cometido que encuentra su punto de partida y de llegada en la propia Constitución, por concederle ésta en su artículo 129.2 un reconocimiento expreso que asegura su desarrollo formal y funcional e integrarlo, al mismo tiempo, como vía para el cumplimiento de los objetivos de contenido social que procura.

Sexta. La colaboración con cooperativas se manifiesta, no sólo como la opción preferente para dar respuesta a las necesidades sociales no suficientemente cubiertas por el Estado, sino también como la forma idea para que los ciudadanos participen más y mejor en los asuntos públicos. Para que, toda vez que se respeten los valores y principios cooperativos, los usuarios de los servicios públicos sean tomados en cuenta para su diseño, planificación y prestación, en aras de su accesibilidad e integridad y, por ende, su calidad.

Séptima. El presente trabajo aborda y pone, por tanto, de manifiesto el proceso de transformación del derecho administrativo vigente en relación con la actividad contractual de las Administraciones y Entidades del Sector Público, con la consiguiente oportunidad de obtener servicios públicos especializados e innovadores.

En este sentido, la gestión de ciertos servicios públicos a través de la adjudicación de contratos del sector público a sociedades cooperativas se presenta no sólo como un reto y oportunidad, sino como uno de los elementos clave en la instauración de una Administración Pública que tenga como meta la realización de los principios constitucionales de eficacia y eficiencia y, a su vez, la protección de los aspectos más sólidos del modelo productivo del sector en que se integra.

\section{Referencias bibliográfícas}

Álvarez Rodríguez, J. F. (2012) El futuro de la economía social. En: Fajardo García, Gemma, y Senent Vidal, María José. Economía social: identidad, desafíos y estrategias. RULESCOOP, Valencia, pp. 405-412.

Argudo Périz, J. L. (2007) Las cooperativas sin ánimo de lucro: ¿vuelta a los orígenes o respuesta a las nuevas necesidades sociales?. Revista Vasca de Economía Social, № 3, pp. 179-201.

Árnaez Arce, V. M. (2012) La compra pública innovadora. La Administración Pública como adquiriente de bienes y servicios innovadores. Revista Vasca de Administración Pública, $\mathrm{N}^{\circ}$ 93, pp. 17-35.

Árnaez Arce, V. M. (2014) La participación ciudadana en la prestación de servicios públicos. El supuesto de las cooperativas de utilidad pública en la Comunidad Autónoma del País Vasco. REVESCO. Revista de Estudios Cooperativos, Tercer Cuatrimestre, № 116, pp. 7-32. DOI: 10.5209/rev_REVE.2014.v116.46578.

Árnaez Arce, V. M. (2018) La alternativa cooperativa en la prestación de servicios públicos sostenibles, Boletín de la Asociación Internacional de Derecho Cooperativo, № 52, pp. 123-135.

Árnaez Arce, V. M. (2018) El modelo cooperativo como alternativa sostenible para la gestión de los servicios públicos en Fomento del Cooperativismo como alternativa económica y social sostenible: una visión de México y España. Madrid: Dykinson, pp. 109-120.

Atxabal Rada, A. y Arnáez Arce, V. M. (2013) Las cooperativas de utilidad pública e iniciativa social. Aspectos administrativos y fiscales. Boletín de la Asociación Internacional de Derecho Cooperativo, No 47, pp. 199-228.

Atxabal Rada, A. (2018) Los impuestos personales sobre el capital en las cooperativas y en sus socios en el País Vasco, Boletín de la Asociación Internacional de Derecho Cooperativo, $\mathrm{N}^{\circ}$ 52, pp. 137-166.

B+I Strategy (2009) Marco Europeo Favorecedor de compras públicas: ventajas, inconvenientes y principales palancas de actuación. Vitoria-Gasteiz: B+I Strategy.

Burzaco Samper, M. (2016) Contrataciones públicas socialmente responsables: la necesidad de reconsiderar el potencial de la contratación pública en la consecución de objetivos sociales. CIRIEC-España, Revista de Economía Pública, Social y Cooperativa, $\mathrm{N}^{\circ}$ 86, pp. 281- 310.

Comisión Nacional de la Competencia. Guía sobre contratación pública y competencia: https://www.cnmc.es/Portals/0/Ficheros/Promocion/Guias_y_recomenda ciones/GUIA_CONTRATACIÓN_v4.pdf (Última consulta, 9 de octubre de 2019).

Consejo Económico y Social Vasco (2015) Comunidad Autónoma del País Vasco. Memoria socioeconómica 2015: http://www.cesegab.com/Portals/0/Libros/MSE2015. pdf (Última consulta, 27 de marzo de 2019).

Crucelegui Gárate, J. L (2011) Los efectos de los cárteles en la innovación y el bienestar social. Conferencia impartida en el Encuentro "La defensa de la competencia como instrumento de modernización de las estructuras económicas", Santiago de Compostela, 5-7 de octubre de 2011.

Divar Garteiz-Aurrecoa, J. (2010) Las cooperativas ante la crisis económica. Boletín de la Asociación Internacional de Derecho Cooperativo, $\mathrm{N}^{\circ} 44$, pp. 263-283.

Gadea Soler, E., Sacristán Bergia, F. y Vargas Vasserot, C. (2009) Régimen jurídico de la sociedad cooperativa del siglo XXI. Realidad actual y propuestas de reforma. Madrid: Dykinson. 
Gallastegi Ormaetxea, I. (2016) El modelo subvencional para el fomento del cooperativismo, a debate. Comunicación presentada en el XVI Congreso de Investigadores en Economía Social y Cooperativa "Economía Social: crecimiento económico y bienestar" organizado por CIRIEC-España y celebrado en Valencia los días 19-21 de octubre de 2016.

García Macho, R. (2011) La transparencia en el sector público. En: Blasco Esteve, A. (Coord.). El derecho público de la crisis económica. Transparencia y sector público. Hacía un nuevo Derecho Administrativo. Madrid: Instituto Nacional de Administración Pública, pp. 249-260.

Gimeno Feliú, J. M. (2015) La reforma comunitaria en materia de contratos públicos y su incidencia en la legislación española. Una visión desde la perspectiva de la integridad. En: Gimeno Feliú, J. M. (Dir.). Las nuevas directivas de contratación pública. Cizur Menor: Aranzadi, pp. 37-106.

Gimeno Feliú, J. M. (2004) Los procedimientos y criterios de adjudicación y la posibilidad de valorar aspectos sociales y medioambientales. En: Gimeno Feliú, J. M. (Coord.). Contratación de las Administraciones Públicas: análisis práctico de la nueva normativa sobre contratación pública. Barcelona: Atelier, pp. 61-94.

Gimeno Feliú, J. M. (2016) Un paso firme en la construcción de una contratación pública socialmente responsable mediante colaboración con entidades sin ánimo de lucro en prestaciones sociales y sanitarias. Observatorio de Contratación Pública, opiniones, $\mathrm{N}^{\mathrm{0}}$ 232, de 9 de febrero de 2016: http://www.obcp.es/index.php/mod. opiniones/mem.detalle/id.232/relcategoria.208/relmenu.3/chk.faf01cea691c17e6c632c328db10de0f (Última consulta, 25 de marzo de 2019).

Giraldo Neira, O. (2003) Identidad, valores y principios cooperativos. Análisis y significados de la Declaración de la Alianza Cooperativa Internacional. Cali: Giraldo Neira.

Juliá Igual, J. F., y Meliá Martí, E. (2004) El futuro del cooperativismo en una Europa en construcción. En: VVAA. El futuro de las cooperativas en una Europa en crecimiento. CIRIEC-España, Valencia, pp. 13-60.

Lesmes Zabalegui, S. (2016) Análisis de las posibilidades prácticas en contratación social en diferentes Administraciones Públicas. Conferencia impartida en el Congreso Internacional "Nueva contratación pública: mercado y medio ambiente", Pamplona, 5 y 6 de octubre de 2016.

Lizcano Álvarez, J. (2014) Transparencia y corrupción a nivel nacional e internacional. Situación y perspectivas. Conferencia impartida en el acto de clausura del curso académico $N^{\circ} 29$ del Club de Encuentro Manuel Broseta, Valencia, 16 de junio de 2014.

Martínez Fons, D. (2009) Documento de trabajo 153/2009: Cláusulas sociales, libre competencia y contratación pública. Madrid: Fundación Alternativas.

Medina Arnáiz, T. (2011) Las principales novedades en la normativa contractual del sector público. En: Bello Paredes, S. A. (Dir.). Comentarios a la Ley de Economía Sostenible. Madrid: La Ley, pp. 119-163.

Moreno Molina, J. A. (2015) La lucha contra la corrupción en la contratación pública. Contratación Administrativa Práctica, $\mathrm{N}^{\circ} 135$, p. 4.

Morillas Jarillo, M. J. (2008) Las sociedades cooperativas. Madrid: Iustel.

Oller Rubert, M. (2015) Notas sobre la gobernanza en la contratación pública: el perfil del contratante como instrumento de transparencia. Contratación Administrativa Práctica, № 135, pp. 46-54.

Palomar Olmeda, A. (2010) Simplificación administrativa. En: La ordenación de las actividades de servicios: comentarios a la Ley 17/2009, de 23 de noviembre. Quadra-Salcedo Fernández del Castillo, T. (Dir.). Cizur Menor: Aranzadi, pp. 338-345.

Razquin Lizarraga, M. M. (2015) Las nuevas directivas sobre contratación pública de 2014: aspectos clave y propuestas para su transformación en España. Revista de Administración Pública, № 196, pp. 97-135.

Razquin Lizarraga, M. M. (2016) Los diversos modos de inclusión de aspectos ambientales en los contratos públicos. Conferencia impartida en el Congreso Internacional "Nueva contratación pública: mercado y medio ambiente", Pamplona, 5 y 6 de octubre de 2016.

Rodríguez Beas, M. (2015) La compra pública innovadora en la nueva Directiva de contratación pública. En: Gimeno Feliú, J. M. (Dir.). Las nuevas Directivas de Contratación Pública. Cizur Menor: Aranzadi, pp. 307-318.

Rodríguez-Arana Muñoz, J. (2016) La dimensión social de la Administración. Jaime Rodríguez-Arana Muñoz, 4 de marzo de 2016: http://rodriguezarana.com/site/?p=2173 (Última consulta, 28 de mayo de 2019).

Sánchez Graells, A. (2014) El nuevo principio de competencia en la Directiva 2014/24: ¿un nuevo juego de presunciones?. Observatorio de Contratación Pública, 9 de junio de 2014: http://www.obcp.es/index.php/mod.opiniones/mem.detalle/id.157/rel categoria.208/relmenu.3/chk.e5b0c1989f6161015284e36d97736551 (Última consulta, 21 de mayo de 2018).

Transparencia Internacional. Curbing Corruption in Public Procurement. A Practical Guide: https://issuu.com/transparencyinternational/docs/2014_anticorruption__publicprocureme?e=249656/8718192 (Última consulta, 9 de octubre2019). 